\title{
MIOCARDITIS FULMINANTE Y ENFERMEDAD DIARREICA AGUDA POR COXSACKIE VIRUS B6
}

\author{
Germán Málaga ${ }^{1, a}$, Oscar Gayoso ${ }^{1, b}$, María de los Angeles Lazo ${ }^{1, c}$, Nancy Torres ${ }^{1, c}$
}

\begin{abstract}
RESUMEN
Presentamos el caso de una paciente joven que presentó choque cardiogénico por virus Coxsakie B6. La paciente acudió a una clínica particular con un cuadro clínico compatible con gastroenterocolitis aguda a la que después de una hora de estar recibiendo hidratación y manejo del cuadro diagnosticado, se agregó hipotensión que llegó al estado de choque, hipoxemia severa y compromiso pulmonar bilateral intersticial por lo que ingresó a Unidad de Cuidados Intensivos, donde recibió manejo de soporte. Debido al cuadro clínico y elevación de enzimas cardiacas se sospechó de compromiso cardiaco, la ecocardiografía evidenció cambios sugerentes de miocarditis. La evolución fue favorable y se le pudo dar de alta después de una semana. El diagnóstico etiológico del cuadro se hizo en el seguimiento, presentando serología con elevación de títulos para virus Coxsakie B6.
\end{abstract}

Palabras clave: Miocarditis, Choque Cardiogénico, Infecciones por Coxsackievirus (fuente:DeCS BIREME).

\section{FULMINANT MYOCARDITIS AND ACUTE GASTROENTERITIS DUE TO COXSACKIE VIRUS B6}

\begin{abstract}
We present the case of a young woman who suffered cardiogenic due to by Coxsackie virus B6. The patient attended a private clinic with an acute gastroenteritis and after one hour of receiving hydratation,she developed hypotension and shock, severe hypoxemia and bilateral lung infiltrate. The patient entered the Intensive Care Unit, where she received hemodynamic support. Due to the clinical picture and cardiac enzymes increase, a cardiac failure was suspected and the echocardiographic findings suggested "myocarditis". The evolution was successful and Coxsackie B6 virus infection diagnosis was made during the follow up by increase of the levels of antibodies for virus Coxsackie B6.
\end{abstract}

Key words: Myocarditis, Shock, Cardiogenic, Coxsackievirus Infections (source: MeSH NLM).

\section{INTRODUCCIÓN}

La miocarditis es una enfermedad no muy conocida que se puede presentar con una sintomatología variada que puede ir desde enfermedad subclínica hasta muerte súbita. Aproximadamente $6-10 \%$ de los casos de cardiomiopatía dilatada de inicio reciente son secundarios a miocarditis ${ }^{(1-5)}$. Su etiología es variada, abarcando causas infecciosas y no infecciosas. La más común es infección viral, entre los cuales el virus Coxsackie destaca como uno de los agentes identificados con mayor frecuencia ${ }^{(6)}$.

La incidencia exacta de miocarditis es desconocida $(5,7)$. Sin embargo, se encuentra evidencia histopatológica de miocarditis en aproximadamente $10 \%$ de los exámenes post mórtem, a pesar que la mayoría de estos pacientes no hubieran manifestado la enfermedad clínicamente ${ }^{(5)}$. Además, se ha observado que cerca del $20 \%$ de casos de muerte súbita en adultos jóvenes y atletas son a consecuencia de miocarditis ${ }^{(8,9)}$. Con respecto a miocarditis fulminante, una investigación encontró una prevalencia de $10 \%$ en casos comprobados por biopsia y $0,9 \%$ de pacientes con falla cardiaca de reciente inicio ${ }^{(10)}$. Durante brotes de infección por virus Coxsackie se ha encontrado una incidencia de $3,5-5 \%$ de miocarditis ${ }^{(6)}$.

\section{REPORTE DE UN CASO}

Paciente mujer de 18 años de edad, natural y procedente de Lima. Refería como único antecedente de importancia alergia a AINES. Acudió por emergencia de una clínica particular, con tiempo de enfermedad de cuatro horas, por presentar en forma brusca, malestar general, nauseas, vómitos y deposiciones líquidas sin moco, ni sangre. En el examen de ingreso se constató que sus

1 Universidad Peruana Cayetano Heredia, Lima, Perú.

a Médico Internista; b Médico Neumólogo; ' Estudiante de Medicina.

Recibido: 10-01-11 Aprobado: 02-02-11 
funciones vitales estaban dentro de límites normales. Se le diagnosticó gastroenterocolitis aguda y deshidratación leve-moderada; en ese sentido, y de acuerdo con los diagnósticos planteados, en el manejo inicial se administró hidratación endovenosa con cloruro de sodio al $9 \%$, pargeverina clorhidrato $10 \mathrm{mg}$ y dimenhidrinato $50 \mathrm{mg}$.

Una hora después de la admisión, la paciente desarrolló un cuadro de hipotensión (presión arterial: 70/50 mmHg) y palidez marcada, recibió tratamiento de soporte, pero ante el deterioro clínico paulatino la paciente fue conducida a la unidad de cuidados intensivos. Debido al antecedente de alergia a antiinflamatorios no esteroideos, el enfoque diagnóstico inicial en $\mathrm{UCl}$ fue: estado de choque séptico vs anafiláctico, gastroenterocolitis y reacción alérgica a medicamentos. Fue tratada con corticoides y epinefrina, además de expansores de volumen, pero al no obtener respuesta adecuada, se procedió al soporte inotrópico y al monitoreo hemodinámico. A las ocho horas del ingreso presentó mayor deterioro clínico y la paciente fue catalogada como portadora de: a) choque distributivo con soporte inotrópico, b) hipoxemia severa, a descartar tromboembolia pulmonar (TEP) con saturación de oxígeno en $65 \%$ y pO2 en 35mmHg por lo que ingresó a ventilación mecánica no invasiva (VMNI), c) compromiso pulmonar bilateral con componente intersticial y micronodular, con sospecha de neumonía atípica por lo que se administró antibioticoterapia con ceftriaxona y levofloxacino.

Debido al cuadro ya descrito, a la mala evolución clínica con el manejo inicial y a los resultados de enzimas cardiacas (troponina-t, Pro-BNP) (Tabla 1) se sospechó de un compromiso cardiaco, por lo que se le practicó un ecocardiograma que fue informado como: Compromiso difuso de la motilidad del ventrículo izquierdo (VI) con fracción de eyección en 35\% y patrón de llenado del VI restrictivo, estudio muy sugerente de miocarditis aguda. Con esos resultados, y dada la evolución descrita, la paciente fue diagnosticada como portadora de estado de choque car-

Tabla 1. Resultados generales de laboratorio

\begin{tabular}{|c|c|c|c|c|}
\hline \multirow[t]{2}{*}{ Análisis } & \multicolumn{4}{|c|}{ Resultados (valores dereferencia) } \\
\hline & Día 1 & Día 2 & Día 3 & Día 4 \\
\hline Hemoglobina (g/dl) & 10,9 & & & \\
\hline Leucocitos $/ \mathrm{mm}^{3}$ & 11700 & & & \\
\hline Plaquetas $/ \mathrm{mm}^{3}$ & 205000 & & & \\
\hline $\begin{array}{l}\text { Velocidad de } \\
\text { sedimentación (mm/h) }\end{array}$ & 10 & & & \\
\hline $\mathrm{CPK}(\mathrm{U} / \mathrm{L})$ & $136(60-218)$ & 63 & & \\
\hline CPK -MB (ng/ml) & $14,7(0,1-4,9)$ & 6,8 & & \\
\hline Troponina T (ng/ml) & $0,445(0-0,100)$ & 0,279 & 0,019 & 0,010 \\
\hline $\begin{array}{l}\text { Proteína C reactiva } \\
\text { (mg/L) }\end{array}$ & $18,3(0-5)$ & & $<5$ & \\
\hline Pro-BNP (pg/ml) & $7,662(0-222)$ & & & \\
\hline Dímero - D (FEU/ml) & 170 (menor de 200) & & & \\
\hline
\end{tabular}

Tabla 2. Resultados de serología infecciosa y autoinmune

\begin{tabular}{|c|c|c|c|}
\hline Análisis & $\begin{array}{l}\text { Resultados } \\
\text { (Al ingreso) }\end{array}$ & $\begin{array}{l}\text { Resultados } \\
\text { (Semana 1) }\end{array}$ & $\begin{array}{l}\text { Resultados } \\
\text { (Semana 2) }\end{array}$ \\
\hline ANA & Negativo & Negativo & \\
\hline Perfil ENA & Negativo & & \\
\hline $\begin{array}{l}\text { Antifosfolípidos } \\
\text { (panel completo) }\end{array}$ & Negativo & & \\
\hline ANCA & $6,8(0-15)$ & & \\
\hline $\begin{array}{l}\text { Factor } \\
\text { Reumatoideo } \\
\text { Citomegalovirus } \\
\text { EbsteinBarr virus } \\
\text { Adenovirus }\end{array}$ & $\begin{array}{l}\text { Negativo } \\
\text { Negativo } \\
\text { Negativo } \\
\text { Negativo }\end{array}$ & $\begin{array}{l}\text { Negativo } \\
\text { Negativo }\end{array}$ & \\
\hline HIV & Negativo & & \\
\hline $\begin{array}{l}\text { Coxsackie B } 6 \\
\text { Coxsackie B1, B3, } \\
\text { B4, B5 }\end{array}$ & $\begin{array}{l}<1: 8 \\
<1: 8\end{array}$ & $\begin{array}{c}1: 16 \\
1: 8\end{array}$ & $\begin{array}{l}1: 32 \\
<1: 8\end{array}$ \\
\hline Coxsackie B2, & $<1: 8$ & $1: 16$ & $<1: 8$ \\
\hline $\begin{array}{l}\text { Echovirus } \\
(4,9,11,30)\end{array}$ & $<1: 8$ & $<1: 8$ & \\
\hline $\begin{array}{l}\text { Micoplasma } \\
\text { penumoniae }\end{array}$ & Negativo & & \\
\hline $\begin{array}{l}\text { Clamidia } \\
\text { pneumoniae (IgM) }\end{array}$ & $<1 / 20$ & & \\
\hline Influenza A-B & Negativo & & \\
\hline $\begin{array}{l}\text { Hemocultivo x } 2 \\
\text { Coprocultivo }\end{array}$ & $\begin{array}{l}\text { Negativo } \\
\text { Negativo }\end{array}$ & & \\
\hline
\end{tabular}

diogénico por miocarditis de etiología por determinar, por lo que se le practicó una serie de exámenes para descartar causas virales y autoinmunes (Tabla 2 ).

La evolución fue favorable lo que hizo posible el retiro de la VMNI después de 24 horas y se empezó a disminuir los niveles de inotrópicos hasta retirarlos por completo a los cuatro días. El seguimiento radiológico, de laboratorio (Tabla 1) y ecocardiográfico fue favorable; el último ecocardiograma realizado previo al alta fue informado como: Cavidades normales, función del VI global y segmentaria normal. Comparativamente ha normalizado función sistólica y diastólica.

La paciente fue dada de alta después de siete días con tratamiento con cefixime $400 \mathrm{mg}$ y levofloxacino $500 \mathrm{mg}$ por cinco días. Acudió a consultorio externo después de una semana, se le realizó nuevos análisis, con resultados de serología diagnóstica (1:32) para Coxsackie B6 (Tabla 2). Seis meses después del alta se le practicó un ecocardiograma, que evidenció preservación y completa normalidad de la función cardiaca.

\section{DISCUSIÓN}

La presentación clínica de miocarditis fulminante normalmente se caracteriza por la presencia de síntomas de in- 
suficiencia cardiaca NYHA clase IV. El cuadro clínico de infección por virus coxsackie suele presentarse con síntomas gripales como fiebre, artralgias y malestar general durante las 2 a 4 semanas previas y el posterior desarrollo de signos de choque cardiogénico como taquicardia, hipotensión, frialdad distal, compromiso hemodinámico marcado y ocasionalmente insuficiencia respiratoria ${ }^{(11)}$.

En el año 2000, se propuso un sistema de clasificación, el cual incluía hallazgos ecocardiográficos, información hemodinámica obtenida por cateterización y el criterio histológico de Dallas ${ }^{(11)}$ para diferenciar miocarditis fulminante de la forma aguda, la cual presenta grave inflamación, menor presión arterial media, mayor frecuencia cardiaca y mayor presión en cuña en aurícula derecha y la pulmonar. Nuestra paciente fue catalogada como portadora de "miocarditis fulminante" $y$, en su caso, la sola presencia de la clínica, la elevación de las enzimas cardiacas y hallazgos ecocardiográficos sugestivos, hicieron innecesario el uso de métodos invasivos.

Usualmente se describen tres fases en la patogénesis de la miocarditis; la primera es daño miocárdico causado directamente por el virus ${ }^{(12)}$, en la segunda fase este daño es mediado por respuesta inmune humoral y celular y en la última fase típicamente desarrollan cardiomiopatía dilatada (CD) por daño miocárdico extensa. Pero, a pesar de esto, se ha observado que los pacientes con miocarditis fulminante que requieren soporte hemodinámico se recuperan en días o pocas semanas con un mejor pronóstico a largo tiempo cuando se comparan con pacientes con miocarditis aguda ${ }^{(10)}$. Se ha postulado al respecto, que es la reacción inflamatoria inicial, que elimina el virus, la que puede inducir a "miocardio atontado" y conducir a disfunción ventricular. Sin embargo, estos pacientes probablemente no entren a la segunda fase ya descrita ${ }^{(13)}$.

Lo interesante de nuestro caso es que se trata de una paciente joven, con un tiempo de enfermedad muy corto, sin síntomas gripales, pero sí con sintomatología gastrointestinal, que en pocas horas desarrolló falla cardiaca y respiratoria, que requirió soporte inotrópico y ventilación mecánica no invasiva. El diagnóstico de miocarditis se realizó por la clínica, los cambios enzimáticos y con el apoyo diagnóstico del ecocardiograma, el cual mostró disfunción sistólica marcada, con fracción de eyección en 35\%. El manejo, como ha sido descrito, fue de soporte y la evolución favorable en corto tiempo (una semana), a pesar de lo "aparatoso" del cuadro clínico al inicio.

Respecto a la etiología de miocarditis, se describen causas de lo más variadas entre las que se destacan las autoinmunes, las asociadas con medicamentos, las asociadas con metales pesados y las más frecuentes son las asociadas con infecciones, entre las que prevalece las de origen viral. El diagnostico diferencial de nuestra paciente, dada la forma de presentación descrita incluyó enfermedades infecciosas, fundamentalmente virales $y$, por tratarse de una mujer joven, también se planteó entre las posibilidades diagnósticas a enfermedades de origen autoinmune, por lo que se solicitó un plan de trabajo que permitió alejar de primera intención que se tratara de enfermedades del tejido conectivo y a algunas infecciones. No se obtuvo ninguna información que permitiera sospechar en etiologías de origen tóxico o asociada con fármacos. Posterior al alta, el diagnóstico etiológico fue esclarecido cuando los resultados demostraron la progresiva elevación de los títulos de anticuerpos para enterovirus después de dos semanas, confirmando el diagnóstico de infección por virus Coxsackie B6.

Actualmente gracias al avance de las técnicas de biología molecular, se ha logrado asociar casos de miocarditis y cardiomiopatía dilatada con cerca de 20 virus. Mientras que la prevalencia de enterovirus disminuyó, la de adenovirus aumentó(14) y recientemente parvovirus B19 ha sido el genoma viral más detectado en casos de miocarditis ${ }^{(15,16)}$. El citomegalovirus (CMV) también ha sido indicado como causa de miocarditis. Roubille y col. reportan a este agente como causante de miopericarditis en un paciente inmunocompetente, indicando, además, que la presentación de miocarditis por CMV se caracteriza por dolor torácico con anormalidades en el EKG y elevación de enzimas cardiacas ${ }^{(17)}$. Teniente y col. reportan el caso de un paciente que desarrolló miocarditis secundaria a infección por virus Epstein Barr, por lo que sugiere pensar en este agente en cuadros febriles sin etiología conocida y con compromiso multiorgánico ${ }^{(18)}$.

Este caso nos demuestra que es importante tener a la miocarditis como un diagnóstico diferencial en pacientes jóvenes que dentro de un cuadro infeccioso "inocente" presenten deterioro clínico marcado, deterioro hemodinámico o compromiso oxigenatorio, los que pudieran ser originados por un compromiso cardiaco no sospechado.

\section{Fuentes de Financiamiento}

Autofinanciado.

\section{Conflictos de Interés}

Los autores declaran no tener conflictos de interés en la publicación del presente artículo.

\section{REFERENCIAS BIBLIOGRÁFICAS}

1. Peters NS, Poole-Wilson PA.Myocarditis - continuing clinical and pathologic confusion. Am Heart J. 1991;121:942-7. 
2. Nemickas R, Fishman D, Killip T, Dalton W, Brynjolfsson G, Robinson et al. Clinical pathologic conference: massive myocardial necrosis in a young woman. Am Heart J. 1978;95:766-74

3. Sobel B. Shock and death in a 43-year-old woman. Am J Med. 1985;79: 245-52.

4. Fenoglio JJ Jr, Ursell PC, Kellogg CF, Drusin RE, Weiss MB. Diagnosis and classification of myocarditis by endomyocardial biopsy. N Engl J Med 1983;308:12-8.

5. Cooper LT. Myocarditis. N Engl. J Med. 2009;360:1526-38.

6. O'Connell JB. Diagnosis and medical treatment of inflammatory cardiomyopathy. In: Topol et al. Cardiovascular Medicine. Philadelphia: Lipincott-Raven; 1998. Cap 100.

7. Brady WJ, Ferguson JD, UIIman EA, Perron AD. Myocardtis: emergency department recognition and managementEmergency medicine clinics of North America.Emerg Med Clin North Am. 2004;22(4):865-85.

8. Quigley PJ, Richardson PJ, Meany BT, Olsen E, Monaghan M, Jackson $\mathbf{G}$ et al. Long-term follow-up of acute myocarditis: correlation of ventricular function and outcome. Eur Heart J. 1987;8:Suppl J:39-42.

9. Dec GW Jr, Palacios IF, Fallon JT, Aretz HT, Mills J, Lee DC et al. Active myocarditis in the spectrum of acute dilated cardiomyopathies: clinical features, histologic correlates, and clinical outcome. N Engl J Med. 1985;312:885-90.

10. McCarthy RE 3rd, Boehmer JP, Hruban RH, Hutchins GM, Kasper EK, Hare JM, et al. Long-term outcome of fulminant myocarditis as compared with acute (nonfulminant) myocarditis. N Engl J Med. 2000;342(10):690-5.

11. Felker GM, Boehmer JP, Hruban RH, Hutchins GM, Kasper EK, Baughman KL et al. Echocardiographic findings in fulminant and acute myocarditis. J Am Coll Cardiol. 2000;36(1):227-232.
12. McManus BM, Chow LH, Wilson JE, Anderson DR, Gulizia JM, Gauntt CJ, et al. Direct myocardial injury by enterovirus: a central role in the evolution of murine myocarditis. Clin Immunol Immunopathol. 1993;68:159-169.

13. Dennert R., Crijns H., Heymans S. Acute viral myocarditis. Eur Heart J. 2008;29,2073-2082

14. Bowles NE, Ni J, Kearney DL, Pauschinger M, Schultheiss HP, McCarthy R, et al. Detection of viruses in myocardial tissues by polymerase chain reaction: evidence of adenovirus as a common cause of myocarditis in children and adults. J Am Coll Cardiol. 2003;42(3):466-472.

15. KühI U, Pauschinger M, Seeberg $B$, Lassner $D$, Noutsias M, Poller W, Schultheiss HP. Viral persistence in the myocardium is associated with progressive cardiac dysfunction. Circulation. 2005;112(13):1965-1970.

16. Mahrholdt H, Wagner A, Deluigi C, Kispert E, Hager S, Meinhardt $\mathbf{G}$ et al. Presentation, patterns of myocardial damage, and clinical course of viral myocarditis. Circulation. 2006;114(15):1581-1590.

17. Roublille C, Brunel AS, Gahide G, Vernhet Kovacsik H, Le Quellec A. Cytomegalovirus (CMV) and acute miocarditis in an inmunocompetentpatient. Intern Med. 2010;49(2):131-3.

18. Teniente M, Casas J, Ortiz P. Pancreatitis, Miocarditis y Nefritis Intersticial asociadas a infección aguda por el Virus Epstein Barr. Rev Gastroenterol Perú. 2009;29(4):367373.

Correspondencia: Germán Málaga Rodríguez.

Dirección: Calle Chavín 159. CC Monterrico. Lima 33.

Teléfono: (511) 992-768300.

Correo electrónico: gmalaga01@gmail.com

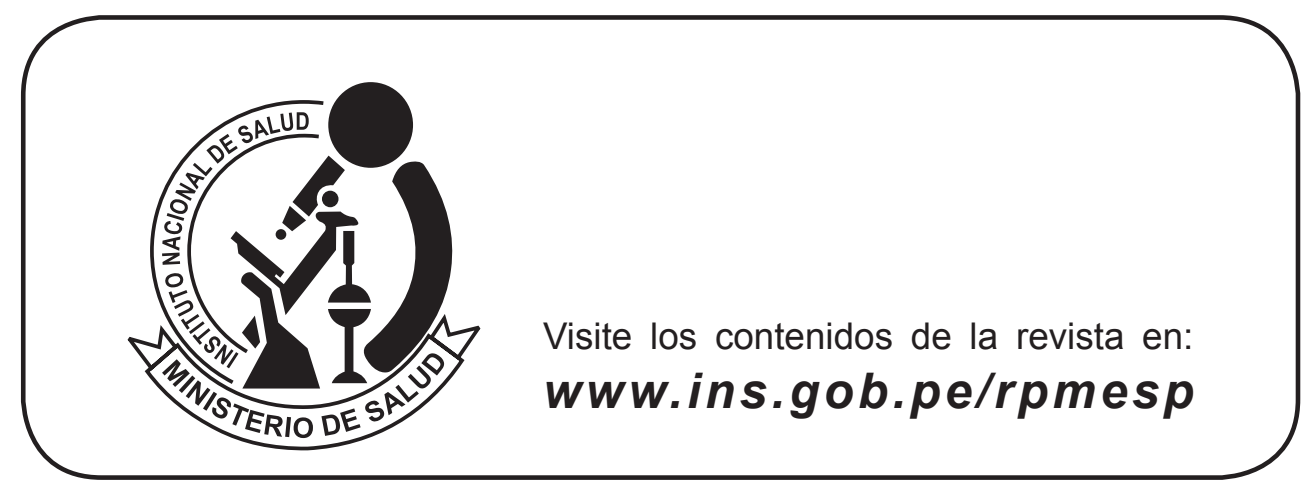

